\title{
Viral causes of unexplained anterior uveitis in Thailand
}

N Kongyai', W Sirirungsi', K Pathanapitoon², N Tananuvat ${ }^{2}$, P Kunavisarut ${ }^{2}$, P Leechanachai ${ }^{1}$, JDF de Groot-Mijnes ${ }^{3,4}$ and A Rothova ${ }^{4,5}$

\begin{abstract}
Aims To assess the possible role of virus infection in patients with unexplained anterior uveitis (AU).

Methods Intraocular fluid and plasma samples of $30 \mathrm{HIV}$-negative $\mathrm{AU}$ patients who were unresponsive or poorly responsive to topical steroid therapy were analyzed for nucleic acid of cytomegalovirus (CMV), herpes simplex virus (HSV), and varicella zoster virus (VZV) by realtime polymerase chain reaction (PCR) and for intraocular antibodies against these viruses by Goldmann-Witmer coefficient (GWC) analysis. Of these 30 cases, 21 were tested for rubella virus by GWC analysis, 16 of which also had PCR assessment of aqueous for rubella virus. Results Viral uveitis determined by either real-time PCR and/or GWC was documented in 20 out of 30 patients $(67 \%)$. Of 30 paired samples tested by both methods for HSV, CMV, and VZV, 15 showed positive results (CMV (10), HSV (4), and VZV (1)). Real-time PCR was positive in $8 / 15(53 \%)$, whereas GWC was positive in 10/15 (67\%). Out of $10 \mathrm{CMV}$-positive patients, four had endotheliitis, two had Posner-Schlossman syndrome, and one Fuchs heterochromic uveitis syndrome (FHUS). Five out of 21 (24\%) samples tested by GWC for Rubella virus were positive, three of which exhibited clinical features of FHUS.

Conclusions Our results indicate that CMV is a major cause of $\mathrm{AU}$ in Thailand and show that FHUS can be caused by both CMV and Rubella virus.
\end{abstract}

Eye (2012) 26, 529-534; doi:10.1038/eye.2011.363; published online 13 January 2012

Keywords: viral anterior uveitis; polymerase chain reaction; Goldmann-Witmer coefficient

\section{Introduction}

Anterior uveitis (AU) is the most frequent anatomic type of uveitis worldwide. ${ }^{1-3}$ Its etiology includes various infectious and non-infectious causes, but remains regularly undetermined. Infectious causes of AU are increasingly being recognized; specifically cytomegalovirus (CMV) and Rubella virus have been reported as infectious causes of AU in immunocompetent patients. ${ }^{3-6}$ Herpetic AU is considered the most common cause of infectious AU in the Western countries. ${ }^{1}$ Recent study from Asia revealed that HIV-negative patients with hypertensive AU regularly had intraocular CMV infection. ${ }^{7}$

Here, we assess the possible role of virus infection in 30 patients with unexplained AU from Chiang Mai, Northern Thailand.

\section{Materials and methods}

Thirty paired intraocular fluid and plasma samples from 30 patients with AU of unknown origin and negative results of the uveitis screening protocol were collected from May 2008 to June 2010 at the Department of Ophthalmology, Faculty of Medicine, Chiang Mai University, Chiang Mai, Thailand. These patients are subgroup of 100 patients with AU seen in this period of time (Figure 1). Samples included in the present study were collected during an active period of intraocular inflammation and included both acute and chronic presentations of AU. The patients who had negative screening results but reacted well to symptomatic treatment and in whom $\mathrm{AU}$ quickly subsided were not sampled. All AU patients underwent a tailored screening protocol, which included chest X-ray and various laboratory tests, including erythrocyte sedimentation rate and complete blood counts, and serology for HIV and Treponema pallidum.

The aqueous sampling was carried out on those with negative initial screening including cases identified as Fuchs heterochromic uveitis syndrome (FHUS) and Posner-Schlossman
${ }^{1}$ Department of Medical Technology, Faculty of Associated Medical Sciences, Chiang Mai University, Chiang Mai, Thailand

${ }^{2}$ Department of Ophthalmology, Faculty of Medicine, Chiang Mai University, Chiang Mai, Thailand

${ }^{3}$ Department of Virology, University Medical Center Utrecht, Utrecht, The Netherlands

${ }^{4}$ Department of Ophthalmology, University Medical Center Utrecht, Utrecht, The Netherlands

${ }^{5}$ Department of Ophthalmology, Erasmus Medical Center, Rotterdam, The Netherlands

Correspondence: K Pathanapitoon, Department of Ophthalmology, Faculty of Medicine, 110 Intawaroros Road, Chiang Mai 50200, Thailand

Tel: + 6653 9455123;

Fax: + 6653946121 .

E-mail: kpathana@

mail.med.cmu.ac.th

Received: 29 March 2011 Accepted in revised form: 25 November 2011 Published online: 13 January 2012 
100 patients

with acute unilateral or bilateral anterior uveitis presenting between 2008-2010

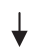

30 patients

with unexplained diagnosis following screening protocol and who failed to respond adequately to topical steroid therapy

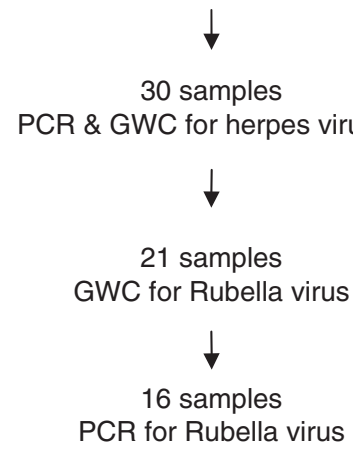

Figure 1 Flowchart of patients with anterior uveitis.

syndrome (PSS). Tuberculin skin test was done if the patients had keratic precipitates (KPs), iris nodules, or chest X-ray suggestive of tuberculosis. HLA-B27 typing was performed if the patients had an acute type of AU. Clinical diagnosis of FHUS was made in six patients who had at least four of the following five signs: (1) unilateral low-grade AU without acute redness, (2) typical scattered KPs, (3) absence of synechiae, (4) diffuse iris atrophy, and (5) cataract. Two patients had recurrent episodes of unilateral low-grade AU with acute onset of highly elevated intraocular pressure (IOP above $40 \mathrm{~mm} \mathrm{Hg}$ ) without any previous therapy. In these two patients, the clinical diagnosis of PSS was made.

Controls consisted of 22 intraocular fluid samples from patients without uveitis collected during intraocular surgery for cataract and retinal disorders including retinal detachment and diabetic retinopathy. This study was performed according to the tenets of the Declaration of Helsinki and with the approval of the local medical ethics committee.

Diagnostic aqueous sampling in uveitis patients was performed as a second diagnostic step in patients with negative initial screening. Aqueous tap was performed with the patient lying down and using a lid speculum. Before the procedure, povidone iodine was used in all patients and after sampling, antibiotic eye drops were applied and the eye was patched for several hours. All samples were stored at $-70{ }^{\circ} \mathrm{C}$ before the laboratory analyses were performed. Intraocular samples were examined for the presence of $\mathrm{CMV}$, herpes simplex virus (HSV)-1 and 2, and varicella zoster virus (VZV) by realtime polymerase chain reaction (PCR) analysis. Nucleic acid was extracted from $25 \mu \mathrm{l}$ of intraocular fluid using the QIAamp DNA Blood Mini Kit (Qiagen, Germantown, MD, USA). To monitor the quality of the extraction and the amplification procedure, $2500-5000$ copies $/ \mathrm{ml}$ of Phocid herpesvirus type 1 were added to each sample before extraction. ${ }^{8}$ The detection of CMV, HSV-1, HSV-2, and VZV DNA was performed at the Division of Clinical Microbiology, Department of Medical Technology, Faculty of Associated Medical Sciences, Chiang Mai University, Chiang Mai, Thailand, as described previously. ${ }^{9}$ The Rubella virus real-time PCR assays were performed at the Virology Department of the University Medical Center Utrecht (Utrecht, The Netherlands), using forward primer 5' GGGAAGTGCGCGATGTTG 3', reverse primer $5^{\prime}$ CGT GGA GTG CTG GGT GAT C $3^{\prime}$ and probe $5^{\prime}$ FAM-AAGCGGGCCATCG-TAMRA $33^{\prime}$.

In addition, Goldmann-Witmer coefficient (GWC) analysis was performed to assess active intraocular production of specific antibodies against CMV, HSV, VZV, and Rubella virus. The amount of specific immunoglobulin G (IgG) against HSV and Rubella virus in plasma and intraocular fluid was determined by the Enzygnost Anti-HSV/IgG and Anti-RV/IgG (Dade Behring, Marburg, Germany), respectively; specific IgG against CMV and VZV was detected by the SERION ELISA classic CMV IgG and varicella zoster IgG kits (Sirion Immunodiagnostica $\mathrm{GmbH}$, Marburg, Germany), respectively. The CMV, HSV, and VZV assays were performed at the Division of Clinical Microbiology, Department of Medical Technology, Faculty of Associated Medical Sciences, Chiang Mai University, Chiang Mai, Thailand and according to the manufacturer's instructions, with adaptations as previously described.9,10 The Rubella virus ELISA were performed at the Virology Department of the University Medical Center Utrecht (Utrecht, The Netherlands) as described previously. ${ }^{5}$ Total IgG concentrations were determined by an in-house ELISA using commercially available reagents. To calculate the total IgG concentration, seven serial twofold dilutions of a nephelometer N Protein standard SL (Dade Behring) were included. Active intraocular antibody production was considered positive if the GWC value was $\geq 3$. ${ }^{9}$

In our study, 30 paired samples were analyzed by both real-time PCR and GWC methods for CMV, HSV, and VZV. Of these, 16 paired samples were available for analysis for Rubella virus infection by both techniques and five patients were investigated for Rubella virus using only GWC analysis (totaling 21 samples investigated by GWC for Rubella virus) (Figure 1).

\section{Results}

The average age of the patients was 45 years and the male-to-female ratio was $1: 1.1$. All control samples were negative in real-time PCR analysis for all tested 
microorganisms. Our positive GWC results were in all cases consistent with the positive PCR results and were positive for solely one out of the three (eventually four tested pathogens).

Results of aqueous sampling by PCR and GWC suggest a viral etiology in 20/30 (67\%) of patients (Table 1). In only 3/30 (10\%) cases was intraocular sampling positive for both PCR and GWC, this being the case for CMV virus only. However, in $12 / 30$ cases (40\%), one or other of GWC or PCR (but not both) gave a positive result for herpes viruses (Table 1). In no case was there a conflicting outcome in showing a positive PCR for one virus type and positive GWC for another virus. PCR and GWC showed a similar percentage of positive results (Table 1). In the cases where rubella virus was tested $5 / 21(24 \%)$ were positive for the virus (GWC). In none of the cases where rubella was tested by PCR was there a positive result. Out of 10 patients with negative results for viruses by either test, three $(30 \%)$ were not tested for rubella virus leaving open the possibility that the overall proportion may be higher.

The clinical features of patients are given in Table 2 . CMV-positive AU was characterized by unilateral AU (90\%), presence of KPs (90\%), and high IOP (60\%). Four of the $10 \mathrm{CMV}$-positive AU patients had endotheliitis and two had associated iris atrophy and cataract (20\%). One VZV patient, diagnosed by real-time PCR analysis, had unilateral chronic AU with KPs, high IOP, and glaucomatous optic neuropathy. None of the HSVpositive AU patients exhibited sector iris atrophy. All Rubella virus-positive AU patients had KPs, four had diffuse iris atrophy, and three exhibited cataract at the first ophthalmologic consultation. Ten patients with undetermined cause of AU did not differ in their clinical characteristics from patients with viral AU (Table 2), specifically their age at onset was similar, majority had unilateral AU (8/10), and KPs (7/10) and increased IOP was documented in 5/10.

Of the six FHUS patients, one patient was positive for CMV by both real-time PCR and GWC analysis, three FHUS patients were positive for Rubella virus by GWC analysis. The remaining two FHUS patients were negative by both techniques for all tested viruses and the origin of their AU was not clarified. One FHUS patient could not be tested for rubella virus; this was the patient with positive CMV results.

Two PSS patients were positive for CMV (one by realtime PCR and the other by GWC analysis).

\section{Discussion}

In this series from Northern Thailand, 20/30 (67\%) immunocompetent patients with negative initial screening for AU were confirmed to have viral AU.

Table 1 Real-time PCR and GWC analysis in 30 anterior uveitis patients

\begin{tabular}{|c|c|c|c|c|}
\hline Assay & $P C R+/ G W C-$ & $P C R+/ G W C+$ & $P C R-/ G W C+$ & Either assay positive \\
\hline CMV & $3 / 10(30 \%)$ & $3 / 10(30 \%)$ & $4 / 10(40 \%)$ & $10 / 30(33 \%)$ \\
\hline HSV & $1 / 4(25 \%)$ & $0 / 4(0 \%)$ & $3 / 4(75 \%)$ & $4 / 30(13 \%)$ \\
\hline VZV & $1 / 1(100 \%)$ & $0 / 1(0 \%)$ & $0 / 1(0 \%)$ & $1 / 30(3 \%)$ \\
\hline Total herpes viruses & $5 / 15(33 \%)$ & $3 / 15(20 \%)$ & $7 / 15(47 \%)$ & $15 / 30(50 \%)$ \\
\hline Rubella virus & $0 / 5$ & $0 / 5$ & $5 / 5$ & $5 / 16^{\mathrm{a}}\left(5 / 21^{\mathrm{b}}\right)$ \\
\hline
\end{tabular}

Abbreviations: CMV, cytomegalovirus; HSV, herpes simplex virus; VZV, varicella zoster virus; PCR, polymerase chain reaction; GWC, GoldmannWitmer coefficient analysis.

${ }^{\mathrm{a}} 16$ available paired samples were tested for Rubella virus PCR and GWC analysis.

${ }^{\mathrm{b}}$ Additional five intraocular fluid samples were analyzed only by GWC analysis.

Table 2 Clinical features and results of laboratory analysis in the patients with viral anterior uveitis

\begin{tabular}{|c|c|c|c|c|c|c|c|c|c|c|c|c|}
\hline $\begin{array}{l}\text { Positive } P C R \text { and/or } \\
\text { GWC results }\end{array}$ & $\begin{array}{c}\mathrm{N} \\
(\mathrm{N}=30)\end{array}$ & $\begin{array}{l}\text { Male: } \\
\text { female ratio }\end{array}$ & $\begin{array}{l}\text { Average age } \\
\text { (years) (range) }\end{array}$ & Endotheliitis & $K P$ & $P S$ & $\begin{array}{l}\text { Iris } \\
\text { atrophy }\end{array}$ & $\begin{array}{l}\text { Unilateral: } \\
\text { bilateral }\end{array}$ & Cataract $^{\mathrm{a}}$ & $\begin{array}{c}I O P \\
>24 m m ~ H g\end{array}$ & Glaucoma & CME \\
\hline CMV & 10 & $6: 4$ & $44(0.33-60)$ & 4 & 9 & 2 & 2 & 9:1 & 2 & 6 & 5 & 1 \\
\hline HSV & 4 & $2: 2$ & 47 (39-60) & 1 & 2 & 0 & 0 & $3: 1$ & 0 & 0 & 0 & 0 \\
\hline VZV & 1 & $0: 1$ & $53(53)$ & 0 & 1 & 1 & 1 & 1:0 & 0 & 1 & 1 & 0 \\
\hline Rubella virus & 5 & $3: 2$ & $48(40-54)$ & 1 & 5 & 1 & 4 & $4: 1$ & 3 & 1 & 1 & 0 \\
\hline Undetermined & 10 & $3: 7$ & $43(5-75)$ & 1 & 7 & 2 & 1 & $8: 2$ & 2 & 5 & 3 & 0 \\
\hline
\end{tabular}

Abbreviations: CMV, cytomegalovirus; HSV, herpes simplex virus; VZV, varicella zoster virus; PCR, polymerase chain reaction; GWC, GoldmannWitmer coefficient analysis; KP, keratic precipitates; PS, posterior synechiae; IOP, intraocular pressure; CME, cystoid macular oedema.

${ }^{a}$ Out of seven patients with cataract, five patients with viral etiology were considered to be uveitis-related (young individuals with cataract present before the steroid treatment), in two patients with AU of undetermined cause, multiple causes (uveitis, treatment, and age) might have contributed to the development of cataract. 
Our data show similar number of positive tests by PCR and GWC, which indicates that both assays appear equally useful in supporting a diagnosis of viral AU. Neither test appears sufficiently sensitive to be used alone. With real-time PCR as a single diagnostic assay, $47 \%$ would have been missed. Using solely GWC analysis 33\% would have been missed (these percentages apply to those testing positive for herpes viruses by any test; Table 1). Our findings support previous reports from France ${ }^{11}$ and the Netherlands, ${ }^{9}$ which showed that combination of GWC analysis and PCR technique increases the proportion of cases identified as having a viral etiology compared with either test used alone.

In our series, CMV was the most frequent identified virus in AU patients. CMV represents a common infection in the general Thai population as the majority of the adult population is seropositive. ${ }^{12}$ Our findings correspond well to previous reports, ${ }^{7,10,13}$ which described CMV-associated AU in the immunocompetent host, presenting mostly as a recurrent unilateral hypertensive $\mathrm{AU}$, sometimes associated with typical corneal endothelial precipitates, iris atrophy, and the absence of posterior synechiae. ${ }^{6,7,14,15}$ In these previous studies, PCR was used as a main diagnostic tool. Our data demonstrate that GWC analysis can contribute to the diagnosis of CMV AU as 4/10 patients were diagnosed solely by GWC.

In our series, 4/30 patients with AU were caused by HSV and one additional case by VZV. In Western countries, the majority of infectious $\mathrm{AU}$ is thought to be of herpetic origin (72/82; $87 \%$ of infectious AU were herpetic; 7/82; $8 \%$ were Lyme disease). ${ }^{16}$ However, no systematic data from Europe or US are available, which would compare HSV, VZV, and CMV prevalences in AU. The prevalence of herpetic AU might also be influenced by the inclusion of patients with epithelial or stromal keratitis associated with AU. In our series, none of the patients included had keratouveitis. In Asian population, the seroprevalence of HSV is about $60 \%$ and $90 \%$ for both VZV and CMV, which is similar to the Western countries. ${ }^{17-19}$ So far, there is no exact explanation for the differences on CMV prevalence in AU between Asia and Western countries. The seroprevalence of HSV, VZV, and CMV is similar and the possible differences could be in part explained by genetic susceptibility or differences in pathogenic strains of the specific viruses. Moreover, the systematic studies on CMV, HSV, and VZV in diverse AU population are missing.

FHUS represents a syndrome of chronic uveitis associated with typical KPs, iris atrophy, and cataract in the absence of synechiae. It is observed in about $2-3 \%$ of all patients in large uveitis surveys. ${ }^{6,20,21}$ Infectious causes of FHUS have long been suspected. An American study reported that Toxoplasma gondii was involved in the pathogenesis of FHUS. ${ }^{22-26}$ In our study, none of the six FHUS patients had typical chorioretinal lesions, but the number of FHUS cases is small. In Europe, Rubella virus infection was frequently linked to FHUS, whereas in Asia CMV has been reported as a frequent causal agent of FHUS. ${ }^{5-7}$ In our report, one of the six FHUS patients was CMV positive by both real-time PCR and GWC analysis, whereas three FHUS patients were Rubella virus positive by GWC analysis. Our study shows that not only CMV but also rubella virus-associated AU may occur in Asia and cause the clinical features typical of FHUS. Unfortunately, due to the limited volume of samples, Rubella infection was examined by PCR in 16 aqueous samples and GWC in 21 paired aqueous and serum samples. This indicates that the real prevalence of Rubella virus in our series of patients with unexplained AU might have been higher. Rubella virus infection was diagnosed by detection of intraocular antibody production solely, which is similar to previous results. ${ }^{4,27-29}$

The clinical sensitivity of PCR and GWC is difficult to assess, as there is no official gold standard defined for these viral uveitis entities. However, from literatures, it is known that PCR has a sensitivity of up to $81 \%$ in detecting VZV or HSV in herpetic AU. ${ }^{30,31}$ Van der Lelij et $a l^{32}$ demonstrated that in AU with sectoral iris atrophy in the absence of keratitis, PCR and GWC were found positive in 54 and $84 \%$, respectively. Previous studies demonstrated that PCR and GWC were tested positive in $71-80 \%$ of cases with hypertensive AU. ${ }^{10,13}$ Chee and $\mathrm{Jab}^{6}$ demonstrated that PCR for CMV was found positive in $52 \%$ of PSS and $42 \%$ of FHUS. There are some differences in the clinical sensitivity between these publications and may be the result of patient group tested or time of sampling. With regard to the latter, it has been demonstrated, that PCR is usually positive in the early stage of viral disease, whereas the GWC becomes positive at later stages, but remains so for a longer period of time. ${ }^{5}$ For Rubella virus, it has been reported consistently that the GWC is positive in virtually $100 \%$ of FHUS cases and that this virus is also strongly associated with incomplete cases of FHUS; PCR is of little value for the diagnosis of Rubella virus associated uveitis. 4,5,26,28,29 It has been shown that the sensitivity of diagnostic tests was influenced by the time interval between the onset of symptoms and sample collection. ${ }^{9}$ Our study included an insufficient number of patients to investigate these associations. Some of our patients may have come late in their disease course due to the limited access to medical care, thus these cases may have biased the outcome of the diagnostic assays toward more positive GWC analyses. In our series, the sensitivity of combination of PCR and GWC to detect a viral cause for screening negative treatment resistant AU appears to be $67 \%$. If we assume a 
false negative rate for both tests on the basis of neither test being very sensitive, then we can assume that some (or possibly all) of the cases which tested negative for both tests were in fact caused by the virus. However, the negative results may also be due to uveitis caused by a virus not tested for (eg Epstein-Bar virus) or non-viral disease. Future analysis with more patients might provide more insight in the relation between the time of sampling and PCR and GWC positivity in our clinical setting.

The limitations of our study include the limited number of patients and suggest that larger studies would give a better estimate of the sensitivity and usefulness of PCR and GWC in the context of otherwise unexplained AU. Furthermore, the limited volume of sample that can be obtained makes it difficult to carry out all tests on every sample means that future studies will need to be clear from the outset about which tests should have priority. Despite low numbers, our study suggests that a viral etiology appears to be a significant factor in otherwise unexplained AU in Thailand. CMV was an important cause in this group of immunocompetent patients, and along with other herpes viruses made up the largest proportion where a viral cause could be identified. This might raise the prospect of more tailored and targeted treatment in this group of patients who may suffer symptoms over a protracted course.

\section{Summary}

What was known before

- Infectious causes of AU are increasingly being recognized; specifically cytomegalovirus (CMV) and Rubella virus have been reported as infectious causes of $\mathrm{AU}$ in immunocompetent patients.

What this study adds

- Cytomegalovirus is a major cause of unexplained anterior uveitis in Thailand and FHUS can be caused by both CMV and Rubella virus.

\section{Conflict of interest}

The authors declare no conflict of interest.

\section{Acknowledgements}

The authors thank Professor Dr Somsanguan Ausayakhun, MD, Head of the Department of Ophthalmology, Faculty of Medicine, Chiang Mai University for her advice and Mr Boonsong Thunjai for technical assistance. This study was supported in part by the combined grants from the Dr P Binkhorst foundation for ophthalmologic research, Nijmegen; Landelijke stichting voor Blinden en Slechtzienden, Utrecht;
Stichting Oog, 's Gravenzande, Dr FP Fischer Foundation, Amersfoort, in The Netherlands, and Office of the Higher Education Commission, Ministry of Education, Thailand.

\section{References}

1 Rathinam SR, Namperumalsamy P. Global variation and pattern changes in epidemiology of uveitis. Indian J Ophthalmol 2007; 55: 173-183.

2 Suhler EB, Lloyd MJ, Choi D, Rosenbaum JT, Austin DF. Incidence and prevalence of uveitis in Veterans Affairs Medical Centers of the Pacific Northwest. Am J Ophthalmol 2008; 146: 890-896.

3 Pathanapitoon K, Kunavisarut P, Ausayakhun S, Sirirungsi W, Rothova A. Uveitis in a tertiary ophthalmology centre in Thailand. Br J Ophthalmol 2008; 92: 474-478.

4 Quentin CD, Reiber H. Fuchs heterochromic cyclitis: Rubella virus antibodies and genome in aqueous humor. Am J Ophthalmol 2004; 138: 46-54.

5 de Groot-Mijnes JDF, de Visser L, Rothova A. Rubella virus is associated with Fuchs heterochromic iridocyclitis. Am J Ophthalmol 2006; 141: 212-214.

6 Chee SP, Jap A. Presumed Fuchs heterochromic iridocyclitis and Posner-Schlossman syndrome: comparison of cytomegalovirus-positive and negative eyes. Am J Ophthalmol 2008; 146: 883-889.

7 Chee SP, Bacsal K, Jap A, Se-Thoe SY, Cheng CL, Tan BH. Clinical features of cytomegalovirus anterior uveitis in immunocompetent patients. Am J Ophthalmol 2008; 145: 834-840.

8 Niesters HG. Standardization and quality control in molecular diagnostics. Expert Rev Mol Diagn 2001; 1: 129-131.

9 de Groot-Mijnes JDF, Rothova A, van Loon AM, Schuller M, Ten Dam-Van Loon NH, De Boer JH et al. Polymerase chain reaction and Goldmann-Witmer coefficient analyses are complimentary for the diagnosis of infectious uveitis. Am J Ophthalmol 2006; 141: 313-318.

10 de Schryver I, Rozenberg F, Cassoux N, Michelson S, Kestelyn P, Lehoang P et al. Diagnosis and treatment of cytomegalovirus iridocyclitis without retinal necrosis. Br J Ophthalmol 2006; 90: 852-855.

11 Fekkar A, Bodafhi B, Touafek F, Le Hoang P, Mazier D, Paris L. Comparison of immunoblotting, calculation of the Goldmann-Witmer coefficient, and real-time PCR using aqueous humor samples for diagnosis of ocular toxoplasmosis. J Cin Microb 2008; 46: 1965-1967.

12 Thammaborvorn R, Mungmee V, Thammanchoteruja L, Kowitdamrong E, Bhattarakosol P. Prevalence of viral infections in clinical specimens at virology laboratory unit during the year 1998 to 2004. Chula Med J 2007; 51: 229-239.

13 van Boxtel LA, van der Leij A, van der Meer J, Los LI. Cytomegalovirus as a cause of anterior uveitis in immunocompetent patients. Ophthalmology 2007; 114 1358-1362.

14 Wakefield D, Chang JH. Epidemiology of uveitis. Int Ophthalmol Clin 2005; 45: 1-13.

15 Markomichelakis NN, Canakis C, Zafirakis P, Marakis T, Mallias I, Theodossiadis G. Cytomegalovirus as a cause of anterior uveitis with sectoral iris atrophy. Ophthalmology 2002; 109: 879-882. 
16 Jakob E, Reuland MS, Mackensen F, Harsch N, Fleckenstein M, Lorenz HM et al. Uveitis subtypes in a German interdisciplinary uveitis center - analysis of 1916 patients. J Rheumatol 2009; 36: 127-136.

17 Smith JS, Robinson NJ. Age-specific prevalence of infection with herpes simplex virus types 2 and 1: a global review. J Infect Dis 2002; 186: S3-S28.

18 Seward J, Jumaan A. VZV: persistence in the population. In: Arvin A, Campadelli-Fiume G, Mocarski E, et al (eds). Human Herpes Viruses: Biology, Therapy, and Immunoprophylaxis. Cambridge University Press: Cambridge, 2007, Chapter 40.

19 Urwijitaroon Y, Teawpatanataworn S, Kitjareontarm A. Prevalence of cytomegalovirus antibody in Thainortheastern blood donors. Southeast Asian J Trop Med Public Health 1993; 24: 180-182.

20 Mohamed Q, Zamir E. Update on Fuchs' uveitis syndrome. Curr Opin Ophthalmol 2005; 16: 356-363.

21 Norrsell K, Sjödell L. Fuchs' heterochromic uveitis: a longitudinal clinical study. Acta Ophthalmol 2008; 86: 58-64.

22 Westeneng AC, Rothova A, de Boer JH, de Groot-Mijnes JDF Infectiuos uveitis in immunocompromised patients and the diagnostic value of polymerase chain reaction and Goldmann-Wimer coefffient in aqueous analysis. Am J Ophthalmol 2007; 144: 781-785.

23 Schwab IR. The epidemiologic association of Fuchs' heterochromic iridocyclitis and ocular toxoplasmosis. Am J Ophthalmol 1991; 111: 356-362.

24 Rehder JR, Burnier Jr MB, Pavesio CE, Kim MK, Rigueiro M, Petrilli AM et al. Acute unilateral toxoplasmic iridocyclitis in an AIDS patient. Am J Ophthalmol 1988; 106: 740-741.
25 Holland GN, Muccioli C, Silveira C, Weisz JM, Belfort Jr R, O'Connor GR. Intraocular inflammatory reactions without focal necrotizing retinochoroiditis in patients with acquired systemic toxoplasmosis. Am J Ophthalmol 1999; 128: 413-420.

26 de Visser L, Rothova A, de Boer JH, van Loon AM, Kerkhoff FT, Canninga-van Dijk MR et al. Diagnosis of ocular toxocariasis by establishing intraocular antibody production. Am J Ophthalmol 2008; 145: 369-374.

27 Rothova A. The riddle of Fuchs heterochromic uveitis. Am J Ophthalmol 2007; 144: 447-448.

28 Ruokonen PC, Metzner S, Ucer A, Torun N, Hofmann J, Pleyer U. Intraocular antibody synthesis against rubella virus and other microorganisms in Fuchs' heterochromic cyclitis. Graefes Arch Clin Exp Ophthalmol 2010; 248: 565-571.

29 Suzuki J, Goto H, Komase K, Abo H, Fujii K, Otsuki N et al. Rubella virus as a possible etiological agent of Fuchs heterochromic iridocyclitis. Graefes Arch Clin Exp Ophthalmol 2010; 248: 1487-1491.

30 Schacher S, Garweg JG, Russ C, Böhnke M. Diagnosis of herpetic uveitis and keratouveitis. Klin Monbl Augenheilkd 1998; 212: 359-362. German.

31 Sugita S, Shimizu N, Watanabe K, Mizukami M, Morio T, Sugamoto $\mathrm{Y}$ et al. Use of multiplex PCR and real-time PCR to detect human herpes virus genome in ocular fluids of patients with uveitis. Br J Ophthalmol 2008; 92: 928-932.

32 Van der Lelij A, Ooijman FM, Kijlstra A, Rothova A. Anterior uveitis with sectoral iris atrophy in the absence of keratitis: a distinct clinical entity among herpetic eye diseases. Ophthalmology 2000; 107: 1164-1170. 